\title{
Como sair do regime liberal de política econômica e da quase-estagnação desde 1990
}

\section{LUIZ CARLOS BRESSER-PEREIRA I}

1

ECONOMIA brasileira está quase-estagnada desde 1980, e em retrocesso econômico desde 2014. Desde 1990 o regime de política econômica é liberal - um regime incompatível com o desenvolvimento do Brasil. Neste artigo, discuto por que e proponho uma política novodesenvolvimentista que resumo em cinco pontos.

Entre 1950 e 1980, a renda por pessoa cresceu 4,5\% ao ano; desde então, cresce menos de 1\% ao ano; em 2014, estagnou; em 2015 e 2016, essa renda caiu mais do que 8\%. Entre 1980 e 2014, enquanto a renda por pessoa dos brasileiros aumentou 1,4 vez, a dos tailandeses, 4 vezes; dos sul-coreanos, 6,3 vezes; e a dos chineses, 17,5 vezes. A maioria dos brasileiros ainda não se deu conta dessa quase-estagnação; que o Brasil está ficando para trás. Os liberal-conservadores reconhecem crises passageiras, decorrentes de irresponsabilidade fiscal como a ocorrida no governo Dilma, mas fora disto estamos sempre "no melhor dos mundos possíveis" do dr. Pangloss.

Por que o Brasil cresce tão pouco há 36 anos, e qual a causa da profunda recessão que hoje experimentamos? A causa da estagnação dos anos 1980 é bem conhecida: o endividamento externo na década anterior - a política de crescimento com "poupança externa" - levou o país a uma brutal crise financeira, e esta, a uma alta inflação inercial - quase uma hiperinflação. Esses problemas foram resolvidos entre 1990 e 1994, quando a crise financeira da dívida externa e a alta inflação inercial foram superadas, mas, no entanto, depois dessa data, a economia brasileira permaneceu quase-estagnada. O que aconteceu nos anos 1990 que levou a economia brasileira a crescer muito menos do que seria lícito esperar?

A resposta que eu tenho dado a essa pergunta é simples: as duas determinantes econômicas do crescimento - a taxa de investimento e a produtividade do capital - caíram desde os anos 1980. A taxa de investimento, que girava em torno de 29\% do PIB nos anos 1970 (a preços constantes), desde a década de 1990 gira em torno de 19\%; a produtividade do capital - a relação produto-capital - de aproximadamente 0,25 nos anos 1970, caiu para cerca da metade nos nossos dias. Por que essa queda da taxa de investimento? E por que a redução da 
eficiência dos investimentos? Se respondermos a essas duas questões, saberemos como sair da crise.

Antes é necessário sair da crise financeira e da recessão atual, mas sua causa está diretamente relacionada com o desestímulo ao investimento produtivo que tem caracterizado a economia brasileira. Por outro lado, sabemos que as crises financeiras são cíclicas, e, mais cedo ou mais tarde, acabam. São causadas pelo mal funcionamento do mercado, e terminam pelas mesmas forças do mercado, mas podem demorar para acabar, e desembocar em baixo crescimento. Antes da teoria macroeconômica de John M. Keynes e Michal Kalecki, os governos não tinham alternativa senão esperar que a recuperação econômica ocorresse. A teoria macroeconômica ofereceu instrumentos - a política fiscal e a política monetária - para que os países evitem as crises, e, quando falham nessa tarefa, para que saiam mais depressa delas. Graças à nova teoria e à nova política econômica, esperava-se que os governos deixassem de agravar as crises, como geralmente o faziam ao decidir cortar as despesas públicas quando a economia entrava em crise. Mas a recessão atual mostrou que os brasileiros ainda não aprenderam o básico da teoria keynesiana. Desde janeiro de 2015, quando a recessão se tornou clara para todos, o governo deu início a uma política de austeridade fiscal pró-cíclica, ao mesmo tempo que aumentava a taxa de juros real básica - a Selic - aprofundando a crise e retardando a recuperação.

Mas deixemos de lado a recessão, que no final de 2017 deverá estar terminando, e vejamos o problema da quase-estagnação de longo prazo. É ela que precisa ser reconhecida e atacada. Porque se isso não for feito, se o governo continuar a entender o problema da economia brasileira como um problema essencialmente fiscal, que o corte de despesas resolverá, sairemos da recessão, mas continuaremos prisioneiros da semiestagnação. O que importa saber é por que caiu a taxa de investimento, e por que caiu a produtividade do capital.

\section{Regime de política econômica liberal}

Eu tenho afirmado, desde Macroeconomia da estagnação (Bresser-Pereira, 2007), que o Brasil caiu em uma armadilha macroeconômica de altos juros e câmbio apreciado, que tira competitividade das empresas industriais e as leva a investir muito menos, enquanto salários e outros rendimentos artificialmente elevados provocam o aumento do consumo com endividamento externo (Bresser-Pereira. 2016, 2017). Acrescento a essa explicação três outros fatos: primeiro, o Estado brasileiro deixou de poupar; ao invés de realizar uma poupança pública, como acontecia nos anos 1970, passou a apresentar uma despoupança pública, que reduziu a capacidade de investimento do Estado, o qual, em princípio, deve ser responsável por cerca de $20 \%$ a $25 \%$ do investimento total. Segundo, a política econômica deixou de neutralizar a tendência à sobreapreciação cíclica e crônica da taxa de câmbio existente nos países em desenvolvimento. Terceiro, houve mudança demográfica - a forte diminuição da natalidade - que esgotou a oferta ilimitada de mão de obra, causou o aumento dos salários, e reduziu a 
taxa de lucro esperada. Por outro lado, a grande desindustrialização ocorrida no período causou diminuição na relação produto-capital ou produtividade do capital, porque implicou transferência de mão de obra de uma atividade com alto valor adicionado por pessoa, que exige trabalhadores e gerentes qualificados, e paga bons salários, como é a indústria, para serviços com baixa sofisticação tecnológica. E completo minha análise com uma explicação cultural: desde a transição democrática de 1985 a população brasileira deixou-se levar por uma alta preferência pelo consumo imediato, e perdeu a ideia de nação, passando a aceitar, docemente, os conselhos e sugestões que vem dos países ricos, nossos concorrentes.

\section{Regime incompatível com o crescimento}

Há uma outra maneira de expressar a mesma ideia. A economia brasileira cresce lentamente desde 1990 porque nessa década o regime de política econômica mudou de desenvolvimentista para liberal. Embora um regime de política econômica desenvolvimentista não assegure o desenvolvimento econômico se for conduzido com incompetência ou de forma populista, um regime liberal é intrinsecamente incapaz de promover o desenvolvimento econômico de um país como o Brasil, independentemente da competência do governo, porque o populismo cambial, que é inerente a esse tipo de regime de política econômica, desestimula o investimento e leva o país a crises cíclicas. Além disso, o regime liberal, embora defenda a responsabilidade fiscal, não defende a poupança pública que resultaria dessa responsabilidade e que permitiria o investimento público um tipo de investimento que é estratégico para o desenvolvimento econômico.

Há dois conceitos de populismo: o político e o econômico; este último, por sua vez, se divide em populismo fiscal e populismo cambial. O populismo político tem uma ampla história por trás. Simplificando muito, seu conceito clássico é o do regime no qual o líder político populista logra estabelecer uma relação direta com o povo sem a intermediação de partidos políticos e de uma ideologia. Geralmente é a primeira manifestação política de um povo que começa a despertar para a política. Mais recentemente tem sido usado por intelectuais liberais para nomear políticos e partidos políticos que adotam uma ideologia nacionalista ou "antiliberal". Nem sempre o populismo político é um mal. Ao contrário, quando expressa o início da participação popular na política, representa um avanço. E o líder populista não precisa incidir também no populismo econômico. Getulio Vargas foi um grande líder populista, mas sempre praticou a responsabilidade fiscal.

Já populismo econômico é o nome de uma prática sempre condenável. É simplesmente o nome da irresponsabilidade no gasto. A expressão foi originalmente utilizada por economistas liberais, a partir dos anos 1980, mas eles o limitaram ao gasto público. Quando um governo gasta mais do que arrecada de forma irresponsável temos o populismo fiscal, que implica o Estado incorrer em elevados déficits públicos; quando, em lugar do Estado é o Estado-nação que 
gasta irresponsavelmente mais que arrecada, temos o populismo cambial, que implica o país incorrer em elevados déficits em conta corrente. Nesse caso, não apenas o Estado, mas também, senão principalmente, o setor privado se envolve na gastança. O populismo fiscal é péssimo, porque desorganiza as finanças públicas; o populismo cambial é pior, porque quebra o país.

Nos países em desenvolvimento, os governos desenvolvimentistas são tentados tanto pelo populismo fiscal como pelo populismo cambial, mas podem evitar os dois erros e serem bem-sucedidos. Já os governos liberais, além de abusarem da austeridade fiscal, incorrem necessariamente no populismo cambial. Eles podem ser bem-sucedidos em conduzir planos de estabilização, como o brasileiro de 1964-1966, mas não têm condições de garantir o crescimento posterior, porque acreditam na política de crescimento com "poupança externa", ou seja, a política de endividamento externo, incorrem tranquilamente em elevados déficits em conta corrente certos que as taxas de poupança e investimento estão aumentando, a taxa de câmbio se aprecia, as empresas perdem competitividade, a industrialização se inviabiliza ou a desindustrialização se desencadeia, e, depois de alguns anos, uma crise financeira termina o breve ciclo de apreciação e crise da moeda nacional.

Essa crítica aos déficits em conta corrente ou à poupança externa é contraintuitiva, porque parece verdade que “os países ricos em capital devem transferir seus capitais para os países pobres em capitais", mas isso só seria verdade em um mundo sem moeda ou no qual a moeda é neutra - o mundo da ortodoxia liberal. No mundo real o déficit em conta corrente implica apreciação da moeda nacional, porque para cada nível de saldo em conta corrente existe uma taxa de câmbio que pode permanecer apreciada no longo prazo sem que a crise financeira se desencadeie, mas deprimindo o investimento e a poupança privada no longo prazo.

Essa crítica ao regime liberal de política econômica não implica rejeição das empresas multinacionais. Elas podem ser úteis para o país se implicarem transferência de tecnologia, ou abertura de novos mercados de exportação. O grande problema são os déficits em conta corrente que elas e o sistema financeiro internacional financiam. São esses déficits que implicam uma taxa de câmbio apreciada no longo prazo, que, de um lado, aumentam os rendimentos e o consumo artificialmente, e, de outro, tornam não competitivas as empresas nacionais de bens tradable não commodity (bens principalmente industriais) e endividam o país. A forma correta de agir é a da China, que apresenta sempre superávits em conta corrente, mantendo, assim, competitivas suas boas empresas. Nesse caso, os investimentos diretos não cobrem um déficit em conta corrente, e, sim, são a contrapartida dos investimentos do país no exterior ou então são utilizados para aumentar suas reservas internacionais.

Em síntese, déficits em conta corrente implicam necessariamente a apreciação cambial, já que existe uma relação direta entre o saldo em conta-corrente 
e a taxa de câmbio. A taxa de câmbio que equilibra um déficit de 3\% do PIB é substancialmente mais apreciada do que aquela que zera a conta corrente. Em consequência, quando o país incorre em déficit em conta corrente, as empresas nacionais produtoras de bens comercializáveis (tradables) perdem competitividade, e não investem, de forma que, ou o país que era industrializado se industrializa, ou é ainda produtor de commodities e terá grande dificuldade em se industrializar. A política de endividamento externo para crescer é essencialmente equivocada a não ser nos breves períodos em que a economia já está crescendo muito rapidamente, a propensão marginal a consumir cai, e, em consequência, a taxa de substituição da poupança interna pela externa cai.

Essa análise vale para os países em desenvolvimento em geral. Se ele, adicionalmente, tiver o problema da doença holandesa, além de rejeitar a política de endividamento externo, ele precisará necessariamente neutralizar essa desvantagem competitiva de longo prazo que resulta da exportação de commodities. Para isso ele deverá impor um imposto ou retenção sobre a exportação de commodities que deverá ser variável, de acordo com o preço internacional da commodity. Em outras palavras, ele deverá ter como meta um superávit em conta corrente, porque a neutralização dessa desvantagem competitiva implica mudar a taxa de câmbio do equilíbrio corrente (que equilibra a conta corrente do país) para o equilíbrio industrial (que torna competitivas as empresas industriais e de serviços tradables), o qual, por definição, corresponde a um superávit em conta corrente.

\section{Regime desenvolvimentista}

Os sistemas econômicos capitalistas são coordenados por duas instituições: o mercado e o Estado. Enquanto os regimes liberais de política econômica buscam reduzir o papel do Estado ao mínimo possível, os regimes desenvolvimentistas atribuem ao mercado o principal papel, mas defendem o planejamento do setor não competitivo de cada economia, e uma política macroeconômica ativa, particularmente uma política cambial. Eles não implicam necessariamente o populismo cambial, mas podem incorrer tanto nele quanto no populismo fiscal.

Entre 1930 e 1990, o Brasil teve um regime de política econômica desenvolvimentista. Foi então que o país formou sua nação, formulou uma estratégia nacional de desenvolvimento, e realizou sua revolução industrial. No quadro desse regime, o país passou por crises (1954-1955, 1961-1964, 1980), nem sempre as políticas adotadas foram acertadas, a desigualdade aumentou no período, mas o fato é que o crescimento econômico foi extraordinário. Nesses 60 anos o Brasil completou sua revolução capitalista. Em 1930 o Brasil era uma sociedade agrário-exportadora dominada por uma oligarquia de senhores de terra e de políticos patrimonialistas. Em 1990, uma sociedade industrial que contava com uma grande classe média, uma classe operária importante, e uma elite de empresários e políticos comprometidos com a industrialização. Nesse período, apenas o Japão cresceu mais do que o Brasil. 
O desenvolvimentismo é uma palavra que serve tanto para designar uma forma de organização econômica do capitalismo voltada para o desenvolvimento econômico e caracterizada por nacionalismo econômico e intervenção moderada do Estado na economia, como uma teoria que busque explicar e oferecer políticas econômicas para essa forma ou esse estilo de capitalismo. Conforme observou de forma aguda Pedro Cézar Fonseca (2015, p.1):

Desenvolvimentismo pertence à mesma família de termos como "ortodoxia", "neoliberalismo" e "keynesianismo", os quais servem para designar alternativamente duas coisas por certo indissociáveis, mas que não são exatamente o mesmo nem do ponto de vista epistemológico, nem na prática cotidiana: i) um fenômeno do "mundo material", ou seja, um conjunto de práticas de política econômica propostas e/ou executadas pelos formuladores de políticas, isto é, fatos concretos ou medidas "reais" que compartilham um núcleo comum de atributos que os caracteriza como tal; e ii) um fenômeno do "mundo do pensamento", ou seja, um conjunto de ideias que se propõe a expressar teorias, concepções ou visões de mundo.

O desenvolvimentismo enquanto forma de organização do capitalismo é alternativo ao liberalismo econômico. Fonseca (2015, p.15), na pesquisa que realizou sobre o assunto, encontrou as primeiras referências ao termo em trabalhos de Hélio Jaguaribe (1962) e Luiz Carlos Bresser-Pereira (1963). Este, segundo assinalou o economista gaúcho, "já falava no "choque do desenvolvimentismo intervencionista contra o liberalismo econômico’ (1963, p.16)”.

Entre os anos 1930 e os 1970, o desenvolvimentismo não foi um regime de política econômica exclusivo dos países em desenvolvimento, embora o nome tenha surgido nos anos 1950 para designar esses países que então buscavam se industrializar. $\mathrm{O}$ desenvolvimentismo, nos 50 anos que vão de $1930 \mathrm{a}$ 1980, foi a forma dominante de organizar as economias dos países capitalistas desenvolvidos. Surgiu como uma reação ao fracasso do liberalismo econômico, que se traduziu no crash da Bolsa de Nova York, de 1929, e na Grande Depressão da década seguinte. O New Deal, nos anos 1930, e os Anos Dourados do Capitalismo, no após-guerra até meados dos anos 1970, ou a coalizão de classes fordista, na linguagem da Escola da Regulação francesa - foram desenvolvimentistas, como foi desenvolvimentista o mercantilismo, no seio do qual as revoluções industriais inglesa e francesa foram realizadas. Entre o primeiro desenvolvimentismo, mercantilista, e o segundo, o fordista, entre os anos 1830 e 1920, Inglaterra e França, que nos servem de parâmetro porque passaram por todas as fases do capitalismo, experimentaram o liberalismo econômico. O segundo desenvolvimentismo começou pelo senso prático dos políticos, a começar por Franklin Delano Roosevelt, que acredito ter sido o maior estadista do século $\mathrm{XX}$, mas recebeu contribuições teóricas dos economistas. A principal foi a teoria da política macroeconômicas de Keynes e Kalecki, mas houve também a contribuição importante da escola "development economics", que hoje eu denomino "desenvolvimentismo clássico". Fizeram parte dessa escola de pensamento eco- 
nômico economistas notáveis como Gunnar Myrdal, Arthur Lewis, Raul Prebisch, Celso Furtado e Albert Hirschman. Eles faziam parte do "mainstream" da época, e o Banco Mundial usava suas teorias para orientar sua ação. Esse banco, que depois iria se tornar o principalmente instrumento do governo americano para levar os países em desenvolvimento a realizar as reformas neoliberais, foi originalmente desenvolvimentista. ${ }^{1}$

A contribuição fundamental do desenvolvimentismo clássico foi a crítica da teoria das vantagens comparativas do comércio internacional que permitia à ortodoxia liberal afirmar que países como o Brasil não precisavam se industrializar. Essa teoria já havia sido criticada por grandes antecessores do desenvolvimentismo clássico, como Alexander Hamilton (2001[1792]) e Friedrich List (1986 [1846]) com a tese da indústria infante. A crítica recebeu novos aportes dos desenvolvimentistas clássicos: a teoria do big push ou desenvolvimento equilibrado, a tese da tendência à deterioração dos termos de troca, e a teoria das duas elasticidades ou da restrição externa, a tese da transferência de mão de obra para setores com maior valor adicionado por pessoa e a tese das economias de escala associadas à indústria. Sua principal conclusão foi a de que desenvolvimento econômico é industrialização, é mudança estrutural, é o que hoje denomino sofisticação produtiva - é a transferência de mão de obra para setores com maior valor adicionado por pessoa, que empregam pessoas mais educadas, e pagam salários maiores.

Armados desse princípio fundamental e da macroeconomia keynesiana, não obstante esta não estivesse dirigida para os problemas do desenvolvimento, os países da periferia do capitalismo construíram uma estratégia nacional de desenvolvimento baseada na proteção à indústria nacional. Configurou-se, então, o modelo de substituição de importações, que era adequado para o início da industrialização, principalmente em países que contassem com um mercado interno amplo. Por isso foi particularmente bem-sucedida em países grandes como o Brasil e o México. Os economistas da época não conheciam a doença holandesa e a forma de neutralizá-la, nem contavam com a crítica da política de crescimento com endividamento externo (esses dois modelos só apareceriam com o novo desenvolvimentismo), mas supunham que desde que impusessem barreiras alfandegárias elevadas para a importação de bens manufaturados, elas seriam suficientes para compensar o problema da indústria nascente. Na verdade, se fossem elevadas, além de proteger a indústria infante, poderiam neutralizar a doença holandesa do ponto de vista do mercado interno. Nessa fase era o que importava. Mas há uma ineficiência básica nesse tipo de modelo, e ele logo se esgota. Como aconteceu com o Brasil a partir de 1967, quando o modelo de substituição de importações já estava esgotado e o desafio era mudá-lo para um modelo exportador de manufaturados, esse desafio foi vitorioso com a adoção de um elevado subsídio às exportações de manufaturados, que neutralizou a doença holandesa também do lado do mercado externo. A indústria se tornava competitiva não apenas no mercado interno, mas também no mercado externo. 
Nos termos do novo desenvolvimentismo, para que uma economia nacional se desenvolva é necessário que os cinco preços (a taxa de lucro, a taxa de juros, a taxa de câmbio, a taxa de salários e a taxa de inflação) estejam certos, e que haja responsabilidade fiscal e cambial. Isso foi relativamente alcançado pelo regime desenvolvimentista de política econômica entre 1930 e 1990. Relativamente porque em alguns momentos (governo Kubitschek, governo Sarney) não houve responsabilidade fiscal. Houve, porém, responsabilidade cambial graças à adoção de vários mecanismos que acabavam por neutralizar pragmaticamente a doença holandesa e graças à indexação da taxa de câmbio, adotada entre 1964 e 1998. Essas políticas permitiram que a taxa de câmbio se mantivesse competitiva e que as empresas industriais competentes prosperassem.

O mesmo aconteceu com a taxa de lucro que é necessária para financiar o investimento, e a taxa esperada de lucro, que é essencial para justificar esse mesmo investimento. Ambas dependem de uma taxa de câmbio competitiva, que o regime desenvolvimentista afinal conseguia administrar de forma satisfatória. Já a taxa de salários cresceu no período menos do que a produtividade, o que não impediu o crescimento, mas o tornou injusto no tempo do nacional-desenvolvimentismo. Quanto à taxa de inflação, ela tendeu a ser alta demais. Desconsiderando o período 1980-1994, no qual a indexação da economia foi a grande responsável pela inflação, há uma explicação básica para essa mesma inflação no período anterior (1930-1980). Naquela época não havia dívida pública, e a inflação atuava como uma válvula de escape através para a irresponsabilidade fiscal dos governos. Desde 1994, agora no quadro da existência de crédito para o Estado e, portanto, de dívida pública, seu crescimento financiado por juros elevados passou a ser a válvula de escape para o mesmo populismo fiscal.

Antes disso, duas políticas equivocadas adotadas pelo regime militar (o sistema formal de indexação dos ativos financeiros, desde 1964, e a política de crescimento com endividamento externo, a partir de 1974) levaram o Brasil à grande crise financeira da dívida externa dos anos 1980, a dez anos de estagnação econômica e a quatorze anos de alta inflação inercial.

Em 1990, debilitado pela crise da dívida externa e pela alta inflação inercial, o Brasil curvou-se à pressão que vinha de fora. Curvou-se porque o poder e a determinação do Ocidente a favor de reformas neoliberais haviam se tornado muito grandes depois do colapso da União Soviética, e porque, diante da crise interna e dessa pressão externa, as elites econômicas brasileiras, que haviam sido dominantemente desenvolvimentistas ou econômico-nacionalistas até os anos 1980, estavam ficando sem argumentos e cederam ao neoliberalismo.

\section{Regime liberal}

A partir de 1990 o Brasil deixou de ter uma política econômica autônoma, e adotou um regime liberal de política econômica. Em 1994 o Brasil afinal estabilizou a alta inflação inercial (indexada) que assolava o país havia 14 anos. Estabilizou-a através de um plano de estabilização heterodoxo - o Plano Real - 
baseado na teoria da inflação inercial. Seria lícito prever que, lograda essa grande vitória, os economistas que comandaram o Plano Real manteriam sua heterodoxia, agora não mais em relação à teoria da inflação, mas em relação à necessária política cambial visando impedir a valorização do real, e o Brasil retomaria o crescimento de forma acelerada. Ao invés, o que vimos foi o governo submeter-se à nova lógica dominante em Washington e Nova York, e adotar uma política econômica ortodoxa ou liberal caracterizada por juros altíssimos e câmbio apreciado. Sem surpresa, o desenvolvimento econômico não foi retomado, e o país experimentou duas crises financeiras (1999 e 2002) e quase-estagnação.

A instalação do regime de política econômica liberal, em substituição ao desenvolvimentista, ocorreu em quatro tranches, entre 1990 e 1999. Em 1990, no governo Collor, a primeira tranche: a abertura comercial, que envolveu a desmontagem do sistema de neutralização da doença holandesa que estava embutido no regime comercial brasileiro desde 1967, sem que nem o governo liberal nem seus críticos soubessem dessa neutralização. Em 1992, após o fracasso do Plano Collor, no quadro de um acordo com o FMI, a segunda tranche: a abertura financeira, ou seja, a perda de controle das entradas e saídas de capital, da taxa de juros e da taxa de câmbio. Em 1995, no governo Fernando Henrique Cardoso, a terceira tranche: a extinção do conceito de empresa nacional e a privatização e desnacionalização dos serviços monopolistas públicos. E em 1999, no mesmo governo, a quarta tranche: a adoção do chamado "tripé macroeconômico": superávit primário (um objetivo legítimo), meta de inflação (na prática, juros muito altos), e câmbio flutuante (na verdade, sobreapreciação de longo prazo da moeda).

O Brasil continuava, assim, preso na armadilha macroeconômica do juro alto e do câmbio apreciado, que inviabiliza o investimento e o crescimento. A "política de desenvolvimento" do governo Cardoso foi de crescimento com endividamento externo, ou seja, com déficits em conta corrente crescentes, financiados por investimento direto e empréstimos ("poupança externa"), que não resultaram em aumento da taxa de investimento, mas em crescimento do consumo. A taxa de substituição da poupança interna pela externa entre $1994 \mathrm{e}$ 1999 superou $100 \%$.

Em 2002 Luiz Inácio Lula da Silva, um político de esquerda, supostamente desenvolvimentista, foi eleito, mas nos seus oito anos de governo ele não propôs qualquer mudança no regime liberal de política econômica; apenas aproveitou o boom de commodities para aumentar em termos reais o salário mínimo - um aumento de $52 \%$, que teve um bem-vindo efeito distributivo. Conforme ocorrera com o governo anterior, a taxa de juros foi mantida em um nível astronômico, e o real, que se depreciara nas crises de balanço de pagamentos de 1999 e 2002, voltou a se valorizar fortemente. Confirmou-se, assim, a tendência à sobreapreciação cíclica e crônica da taxa de câmbio: em 2002, com a crise financeira, o real tornou-se altamente depreciado; em 2005 tornou-se equili- 
brado, apresentando um pequeno superávit em conta corrente; mas a marcha da apreciação continuou, e, a partir de 2007, a moeda voltou a ficar altamente apreciada. Permaneceu assim (em torno de $\mathrm{R} \$ 2,80$ por dólar, enquanto o equilíbrio industrial estava subindo de $\mathrm{R} \$ 3,80$ para $\mathrm{R} \$ 4,00$ por dólar) até que, no segundo semestre de 2014, nova crise financeira, desta vez das empresas, levou o real a depreciar fortemente, encerrando-se o ciclo. Já no plano fiscal, o governo Lula agiu de maneira responsável. Só expandiu fortemente a despesa em 2009, como reação contracíclica à crise financeira global de 2008. No plano cambial, porém, nada ficou a dever ao governo Cardoso. Cumprindo o programa da ortodoxia liberal - o de crescimento com poupança externa - incorreu igualmente no populismo cambial.

Nesses dezesseis anos de regime liberal (governos Cardoso e Lula), o crescimento foi insuficiente, exceto no momento do boom de commodities (20062008). E, como é norma nos países em desenvolvimento que adotam o receituário liberal, houve responsabilidade fiscal (superávit primário que mantém estável da dívida pública em relação ao PIB) e irresponsabilidade cambial: déficits em conta corrente que implicam sobreapreciação cambial, rendimentos artificialmente elevados, e consumo acima das possibilidades do país.

Nos quatro anos seguintes (2011-2014), a presidente Dilma Rousseff tentou voltar ao regime desenvolvimentista de política econômica, mas havia recebido de Lula uma terrível herança: uma taxa de câmbio de $\mathrm{R} \$ 2,20$ por dólar quando a taxa de câmbio de equilíbrio industrial estava em torno de R $\$$ $3,80 .^{2}$ Afinal, seu governo acabou marcado pela irresponsabilidade tanto cambial quanto fiscal. Em julho de 2011, houve uma rápida e incompetente tentativa de mudar o regime de política econômica através da simples baixa da taxa de juros básica do Banco Central, sem que essa fosse acompanhada por um ajuste fiscal. A Selic chegou em termos reais a $2 \%$ ao ano - o que deixou indignadas as elites financeiro-rentistas e a classe média tradicional, igualmente rentista, que, beneficiadas desde 1964 e, particularmente, desde 1994, acreditam ter "direito" a uma taxa de juros real elevada. As elites financeiro-rentistas haviam sido muito bem tratadas nos dois governos anteriores. Agora eram atacadas no que era mais sagrado para elas: os juros que o Estado lhes paga: a taxa básica de juros que, no Brasil, remunera não apenas as reservas dos bancos, mas também os títulos do Tesouro de longo prazo.

No segundo semestre desencadeou-se nova crise financeira, dessa vez combinada por gravíssima recessão. O gatilho foi a violenta queda dos preços das principais commodities exportadas pelo Brasil durante 2014. Sua causa principal foi a mesma causa macroeconômica da quase-estagnação desde 1990: a combinação de altos juros e câmbio apreciado. Como vimos, no último ciclo o real permaneceu sobreapreciado durante sete anos - do segundo semestre de 2007 ao primeiro semestre de 2014. Desde 2013 o mercado já estava sinalizando a necessidade de depreciação cambial, mas essa foi impedida pelas compras (swaps) de reservas pelo Banco Central. Em 2014, com a queda do preço da soja e do 
minério de ferro, o governo não teve mais forças para resistir, e a moeda se depreciou. Dado esse gatilho, a crise financeira das empresas industriais, que estava sendo construída desde que a taxa de câmbio voltara a se tornar sobreapreciada em 2007, as empresas perderam competitividade, seus lucros caíram, se não se tornaram negativos, e elas começaram a se endividar a altas taxas de juros. Sete anos depois seu endividamento torna-se insustentável, e elas suspendem seus investimentos, desencadeando-se a recessão.

Em síntese, no regime liberal de política econômica, iniciado em 1990 e que dura até hoje, a economia brasileira permaneceu semiestagnada. Os liberais dirão, como sempre, que o problema foi não ter havido mais liberalização, mais privatização, mais desregulação, mas isso faz pouco sentido; é pura ideologia. E que a responsabilidade fiscal não foi tão grande quanto deveria ter sido, o que é sempre verdade, mas não diz muita coisa. O certo é que nesse período os governos mostraram mais responsabilidade fiscal do que cambial. A irresponsabilidade fiscal ocorreu em dois períodos, 1995-1998 e 2011-2014, enquanto a irresponsabilidade cambial atravessou todo o período, com duas breves interrupções, 1999-2003 e 2014-2015, causadas por crises financeiras que depreciaram a moeda. Devido à irresponsabilidade cambial e às altas taxas de juros, a taxa de câmbio ficou em grande parte do período sobreapreciada, e, em consequência, a taxa de lucro esperada pelas empresas de bens comercializáveis não commodities (essencialmente as empresas industriais) foi altamente insatisfatória, enquanto a taxa de salários tornava-se relativamente alta, devido a essa mesma sobreapreciação, ao esgotamento da oferta ilimitada de mão de obra, e ao pleno emprego atingido na virada do século, não obstante as baixas taxas de crescimento. Em síntese, no regime liberal de política econômica os preços macroeconômicos ficaram quase todo o tempo errados, e, assim, explicam a quase-estagnação.

Os quatro anos que antecederam diretamente a última crise foram caracterizados por forte populismo fiscal - o que facilitou o eterno diagnóstico dos economistas liberais que o problema da economia brasileira é o fiscal. É um diagnóstico padrão para quem adota o quadro teórico neoclássico ou ortodoxo, que, como supõe o bom funcionamento dos mercados, não tem outra explicação para as crises e o baixo crescimento, senão que elas são causadas por irresponsabilidade fiscal. A ortodoxia liberal argumenta também sobre falta de poupança, e sobre choques exógenos, mas o primeiro é um problema cuja solução implica estímulo ao investimento e mecanismos de poupança forçada, e o segundo é externo ao sistema econômico. Admitir que o baixo crescimento possa ser explicado pela falta de demanda, ou por falta de investimentos públicos, ou por taxa de juros exorbitantes incompatíveis com a abundância de capitais existentes, ou por falta de acesso à demanda causada por uma taxa de câmbio apreciada no longo prazo é algo impossível para eles, porque tais explicações não estão nos seus livros-texto. E, no entanto, a quase-estagnação brasileira tem essas causas: falta de poupança e investimento público, taxas de juros escorchantes, e sobreapreciação cambial no longo prazo, só interrompida por crises financeiras. 


\section{Cinco pontos}

Diante do quadro de recessão e de quase-estagnação, o que fazer? Não tanto para o país sair da recessão, porque isto já deve estar começando a acontecer depois de uma longa e profunda recessão, mas para evitar que o país volte a mergulhar na semiestagnação que resulta do regime liberal de política econômica adotado no Brasil desde 1990.

Os liberais dizem que para o país crescer basta poupar mais e ter responsabilidade fiscal. Não é assim. Maior poupança é necessária, mas depende do investimento, mecanismos de poupança forçada, e de mudança de atitude cultural difícil de ser lograda; maior responsabilidade fiscal é necessária, mas não suficiente. É preciso reformar o regime de política econômica é torná-lo novamente desenvolvimentista - é levar o Estado a realizar poupança pública e investir; é levar as empresas a pagarem juros menores e a ter melhores expectativas de lucro. Mas isso não significa voltar ao nacional-desenvolvimentismo. O Brasil está em outro estágio de desenvolvimento, e conta com uma teoria nova para orientar a política econômica: o novo desenvolvimentismo. Ao invés do nacional-desenvolvimentismo, sua estratégia deve ter como referência países de renda média. Poderia ser chamada "social-desenvolvimentista", porque deve combinar desenvolvimento econômico com redução da desigualdade e proteção do ambiente, mas isto diz muito pouco sobre a estratégia necessária.

Para a perspectiva novodesenvolvimentista, o novo regime desenvolvimentista de política econômica deve estar baseado em cinco pontos que estão diretamente relacionados com seu respectivo sistema teórico:

1. Deve ter uma regra fiscal contracíclica que limite o gasto público a uma porcentagem do PIB, torne-o contracíclico, e que assegure prioridade à educação e à saúde.

2. Deve buscar definir um nível de taxa de juros, em torno da qual o Banco Central realiza sua política monetária, o mais baixo possível.

3. Deve apresentar um superávit em conta corrente compatível com uma taxa de câmbio competitiva.

4. Deve estar apoiado em um acordo social garantindo salários aumentando com a produtividade e uma taxa de lucro media satisfatória, que motive os empresários a investir.

5. Deve incluir uma reforma tributária que torne os impostos progressivos, e financiem um Estado do bem-estar social.

Creio que os cinco pontos são autoexplicativos, mas vejamos cada um deles rapidamente. O ponto $\mathrm{I}$ - regra fiscal contracíclica - acentua a importância da responsabilidade fiscal, afirma que uma regra fiscal é necessária, que deve expandir o gasto nas recessões e diminuí-lo nas expansões, e deve manter o gasto público dentro de uma porcentagem do PIB, ao invés de ser uma regra fiscal que congele o gasto real, e, portanto, implique a redução do tamanho do Estado. 
O ponto 2 - nível da taxa de juros - supõe que a taxa de juros básica é um instrumento legítimo de controle da inflação, mas não há razão para que seu nível, em torno do qual o Banco Central realiza sua política monetária, seja tão alto como é no Brasil. Esse nível tem baixado desde o Plano Real, mas muito lentamente, com a justificativa de que o nível alto reflete a falta de confiança na capacidade do Estado de pagar sua dívida. Mas o razoável desempenho fiscal desde 1990 não legitima essa explicação. Uma taxa de juros mais baixa é essencial para estimular as empresas a investir, e para distribuir melhor a renda, remunerando menos os capitalistas rentistas que hoje constituem a classe ociosa, como no passado, quando a aristocracia proprietária de terras é que gozava desse privilégio.

O ponto 3 - superávit em conta corrente - afirma que o investimento privado e, portanto, o desenvolvimento econômico depende de uma taxa de câmbio competitiva; que existe uma relação direta entre o saldo em conta corrente e a taxa de câmbio, de forma que quando um país decide crescer com déficit em conta corrente e endividamento externo, está decidindo apreciar a moeda nacional e criar uma desvantagem competitiva para as empresas do país.

O ponto 4 - acordo social - sugere que o desenvolvimento econômico depende de um projeto de nação ou de um acordo nacional que leve à formação de uma coalizão de classes desenvolvimentista formada pelas classes diretamente voltadas para a produção - os empresários, as classes populares formadas por trabalhadores e empregados, e frações da classe tecnoburocrática ou profissional, particularmente a burocracia pública. A essa coalizão, necessária para o desenvolvimento e o catching up, se opõe à coalizão de classes liberal, formada pelos capitalistas rentistas, inclusive a classe média tradicional, e os interesses estrangeiros. O ideal seria que o aumento dos salários fosse maior do que o aumento da produtividade; mas isso só será possível sem prejuízo para uma taxa de lucro satisfatória se (a) a taxa de lucro estiver anormalmente alta; ou (b) o salário mínimo for muito baixo, porque, nesse caso, o aumento não contamina os salários mais altos; ou (c) o progresso técnico for poupador de capital, estando a produtividade do capital aumentando no momento do aumento dos salários.

O ponto 5 - impostos progressivos - completa o compromisso do projeto nacional com a diminuição da desigualdade, que já estava presente na demanda de juros mais baixos, e na necessidade de um acordo social. No quadro do novo desenvolvimentismo, e ao contrário do saber convencional, expansão fiscal não é política de distribuição da renda, e só é legítima quando for contracíclica, ou quando for o resultado de um acordo de aumento de impostos para financiar gasto social adicional. Impostos progressivos e a existência de um Estado do bem-estar social são os instrumentos fundamentais visando reduzir as desigualdades.

Note-se que não estou propondo o fechamento da economia. $\mathrm{O}$ novo desenvolvimentismo defende a abertura comercial e a competição. O que ele cri- 
tica é a desigualdade na competição causada por juros muito altos e taxa de câmbio apreciada no longo prazo. O Grupo Reindustrialização, do qual faço parte, aprovou dois documentos, um em outubro de 2015 e o outro em outubro de 2016, nos quais defende a redução das atuais tarifas alfandegárias para menos da metade, desde que o governo se comprometa com uma taxa de câmbio competitiva, flutuando em torno de $\mathrm{R} \$ 3,80$ por dólar. Quanto à abertura financeira, não estou propondo a volta ao sistema rígido de controle dos movimentos de capital que existiu até 1992; defendo apenas que as autoridades monetárias tenham a possibilidade de recorrer ao controle de capitais. A fuga de capitais que, com frequência, preocupa os dirigentes dos países em desenvolvimento, decorre da política de crescimento com endividamento externo, e da consequente fragilidade financeira desses países.

Os obstáculos para essa mudança de regime de política econômica são de duas naturezas. Há os obstáculos “externos” - a reação dos rentistas, dos financistas, dos interesses estrangeiros, e dos economistas liberais que representam esses grupos. São óbvios, e formidáveis, porque eles contam com a hegemonia ideológica mundial do neoliberalismo financeiro-rentista. E há os obstáculos "internos" - daqueles que serão beneficiados com a política no médio prazo, mas suportarão um custo no curto prazo. Esse é o caso dos trabalhadores e empregados, da classe média profissional, e dos intelectuais e ativistas de esquerda, que terão que reduzir seu consumo no curto prazo, em troca de maiores salários e mais emprego no médio prazo.

Em princípio, o segundo tipo de obstáculo seria mais fácil de vencer. Mas há uma dificuldade cultural importante. Os brasileiros são vítimas de uma alta preferência pelo consumo imediato e da perda da ideia de nação.

Quanto ao problema da demanda excessiva de bens e serviços de consumo, esse é um problema antigo que se agravou com a democracia. Celso Furtado não cansou de criticar a tentativa dos brasileiros de reproduzir os padrões de consumo do centro. Essa atitude dificulta enormemente a adoção de políticas econômicas racionais. O segundo obstáculo deriva diretamente da hegemonia ideológica do Ocidente - o conjunto dos países liderado pelos Estados Unidos. Hoje esse país enfrenta grave crise política com a eleição de Donald Trump, mas são um país poderoso desde a Segunda Guerra Mundial e tornaram-se poderosíssimos com o colapso da União Soviética. O Ocidente não tem interesse no desenvolvimento dos países da periferia do capitalismo; quer apenas ocupar seus mercados internos com suas empresas multinacionais, com seus financiamentos, e com o comércio desigual. A grande dificuldade que os países ricos enfrentavam era neutralizar os líderes nacionalistas ou desenvolvimentista. Mas, desde 1990, essa dificuldade diminuiu substancialmente porque o Ocidente, suas elites e seus economistas, voltaram a ter sucesso em convencer as elites econômicas do país em desenvolvimento de uma tese central no pensamento liberal - que o desenvolvimento econômico não implica industrialização. Ora, os países crescem 
quando suas elites possuem um projeto de nação e sabem distinguir as políticas que promovem o desenvolvimento das políticas que não interessam ao país, apenas facilitando a ocupação de seu mercado interno pelos países ricos. Nenhum país cresce e realiza o alcançamento se não tiver uma clara ideia de nação, e souber definir um projeto nacional. O Brasil não tem uma nação forte e um projeto de desenvolvimento desde 1980.

\section{Notas}

1 Discuti essa questão em "Development economics and World Bank's identity crisis" (Bresser-Pereira, 1995).

2 Hoje o equilíbrio industrial está em torno de $\mathrm{R} \$ 4,00$ por dólar devido ao aumento do custo unitário do trabalho (salário dividido por produtividade) que ocorreu entre 2011 e 2014.

\section{Referências}

BRESSER-PEREIRA, L. C. O empresário industrial e a Revolução Brasileira, Revista de Administração de Empresas v.2, n.8, p.11-27, 1963.

Development economics and World Bank's identity crisis. Review of International Political Economy, v.2, n.2, p.211-47, Spring 1995.

Macroeconomia da estagnação. São Paulo: Editora 34, 2007.

A construção política do Brasil. 3.ed. São Paulo: Editora 34, 2016.

Brazil's 36 years-old quasi-stagnation: facts and theory. To be published in: Edmund Amann, Carlos Azzoni and Werner Baer (in memorian). Oxford Handbook on the Brazilian Economy. Versão de fevereiro de 2017.

FONSECA, P. C. D. Desenvolvimentismo: a construção do conceito. Texto para Discussão IPEA 2103, Julho 2015.

HAMILTON, A. Report on Manufactures, report to the Congress of the US as Secretary of the Treasury. Escaneado em janeiro de 2001 com base em fontes primárias. Disponível em: <http://bit.ly/lFaVTTg>.

JAGUARIBE, H. Desenvolvimento econômico e desenvolvimento político. Rio de Janeiro: Fundo de Cultura, 1962.

LIST, F. O sistema nacional de economia politica. São Paulo: Editora Nova Cultural, 1986. (Coleção Os Economistas. Publicação original em alemão, 1846).

RESUMO - O Brasil cresceu de maneira extraordinária entre 1930 e 1980 sob um regime desenvolvimentista de política econômica; está quase-estagnado desde 1990 sobe um regime liberal. Lula nada fez para mudá-lo; Dilma Rousseff tentou, em 2011, mas logo bateu em retirada. O liberalismo financeiro-rentista é incompatível com o crescimento, porque mantém juros elevadíssimos e câmbio apreciado no longo prazo, que inviabilizam a poupança pública e o investimento privado. Para sair da quase-estagnação, cinco pontos de um regime desenvolvimentista: regra fiscal responsável, juros moderados, câmbio competitivo, acordo social, impostos progressivos. 
PALAVRAS-CHAVE: Regime desenvolvimentista de política econômica, Regime liberal, Quase-estagnação, Juros, Taxa de câmbio.

ABSTRACT - Brazil has grown extraordinarily between 1930 and 1980 under a regime of developmental economic policy; since 1990, it is quasi-stagnant under a liberal regime. Lula did nothing to change it. Dilma Rousseff tried, in 2011, but soon withdrew. Rentier-financier liberalism is incompatible with growth, because it keeps interest rates very high and the exchange rate overvalued in the long-term, which makes public savings and private investment unfeasible. To come out of quasi-stagnation, five points of a developmental regime: responsible tax rule, moderate interest rates, competitive foreign exchange rates, social agreement, and progressive taxes.

KEYWORDS: Developmental economic policy regime, Liberal regime, Quasi-stagnation, Interest rates, Exchange rate.

Luiz Carlos Bresser-Pereira é professor emérito da Fundação Getulio Vargas (SP). @ - bresserpereira@gmail.com

Recebido em 3.3.2017 e aceito em 20.3.2017.

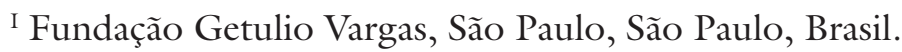

